\title{
Biological treatment and thickening with a hollow fibre membrane bioreactor
}

\author{
Zsirai $^{1}$, T., Wang ${ }^{2}$, Z-Z, Gabarrón ${ }^{3}$, S., Connery ${ }^{4}$, K., Fabiyi ${ }^{4}$, M., Larrea, A ${ }^{4}$, and Judd ${ }^{1 *}$, S.J. \\ ${ }^{1}$ Cranfield Water Science Institute, Cranfield University, Beds., UK, MK43 0AL. ${ }^{2}$ College of Architecture and \\ Civil Engineering, Beijing University of Technology, Beijing, China, 100124. ${ }^{3}$ LEQUIA. Institute of the \\ Environment. University of Girona, Campus Montilivi, E-17071 Girona, Spain. ${ }^{4}$ Praxair International, 7000 \\ High Grove Blvd., Burr Ridge, IL 60527. \\ *Corresponding author: s.j.judd@cranfield.ac.uk, +44 1234758310.
}

\begin{abstract}
Aerobic operation of an immersed hollow fibre membrane bioreactor, treating municipal wastewater supplemented with molasses solution, has been studied across mixed liquor suspended solids (MLSS) concentrations between 8 and $32 \mathrm{~g} \mathrm{~L}^{-1}$, the higher concentrations being normally associated with thickening operations. Only a marginal loss in membrane permeability was noted between 8 and $18 \mathrm{~g} \mathrm{~L}^{-1}$ when operation was conducted without clogging. The sustainable operational flux attainable above $18 \mathrm{~g} \mathrm{~L}^{-1}$ was highly dependent upon both the MLSS concentration and the state of the membrane. A temperature-corrected flux of $28 \mathrm{~L} \mathrm{~m}^{-2} \mathrm{~h}^{-1}$ (LMH) was sustained for 18 hours at an MLSS of $8 \mathrm{~g} \mathrm{~L}^{-1}$ using membranes close to initial their virgin-state permeability. This value decreased to around 14 $\mathrm{LMH}$ at $20 \mathrm{~g} \mathrm{~L}^{-1}$ and $5 \mathrm{LMH}$ at $32 \mathrm{~g} \mathrm{~L}^{-1}$ MLSS for an aged membrane whose permeability had been recovered following clogging. Below the threshold flux operation without significant clogging was possible, such that the membrane permeability could be recovered with a chemically enhanced backflush (CEB). Above this threshold flux clogging took place at a rate of around 7-14 g solids per $\mathrm{m}^{2}$ membrane per $\mathrm{m}^{3}$ permeate volume passed irrespective of the MLSS concentration. The permeability of the unclogged membrane was depressed and could not be recovered using a standard CEB, indicative of irrecoverable pore clogging. The outcomes corroborated previously reported observations concerning the deleterious long-term impacts of clogging, and confirmed the critical importance of operation at a sustainable flux value.
\end{abstract}

Keywords: $\quad$ Membrane bioreactor; thickening; clogging; fouling; sludge.

\section{Introduction}

The study of crossflow membrane filtration for the thickening of waste activated sludge (WAS) dates back at least 20 years (Reed et al, 1993). The use of immersed membranes, both hollow fibre (HF) and flat sheet (FS), for this duty has been a viable commercial process for at least 15 years. Such thickeners are installed at some municipal wastewater immersed membrane bioreactor (iMBR) plants as a supplementary process step for thickening the waste activated sludge from the primary biological treatment process (Judd and Judd, 2010). There were, for example, 26 MBR membrane thickeners installed in North America between 2004 and 2010 based on a single FS technology (Woo, 2010). In such cases the immersed membrane thickening technology employs the same membrane technology as that used for the primary MBR process, but operates at relatively low flux (7-16 compared with $>20 \mathrm{~L} \mathrm{~m}^{-2}$ $\mathrm{h}^{-1}$, or LMH), and relatively high membrane air scour rates $(0.75-1.2$ compared with $<0.5$ $\mathrm{Nm}^{3} \mathrm{~h}^{-1} \mathrm{~m}^{-2}$ ), attaining solids concentrations of up to $5.5 \mathrm{~g} \mathrm{~L}^{-1}$, significantly reducing the sludge volume and thus sludge disposal costs. 
Notwithstanding the existence of these full-scale installations, there appear to be very few studies of immersed membrane thickening of WAS, or of iMBR operation at excessively high sludge concentrations generally. Whilst it is generally recognised that higher mixed liquor suspended solids (MLSS) concentrations tend to depress foulant levels, manifested as soluble microbial product (SMP), such observations have tended to be limited to moderate MLSS concentrations of up to $25 \mathrm{~g} \mathrm{~L}^{-1}$ (Yeom et al, 2005; Schwarz et al, 2006). A body of work specifically on simultaneous aerobic digestion and thickening of WAS (Wang et al, 2008, 2009; Wu et al, 2009) was focused largely on the soluble foulant levels, manifested as soluble microbial product (SMP) and colloidal and/or soluble chemical oxygen demand (sCOD), and bulk sludge quality parameters such as viscosity and capillary suction time (CST). Results showed SMP and SCOD to significantly influence membrane fouling. However, reported outcomes have also suggested permeability decline to be primarily affected by the change in sludge viscosity, and subsequently the required membrane aeration rate, at high MLSS concentrations (Trussell et al., 2007). Other studies have demonstrated decreased dewaterability with increasing sludge concentration associated with the development of filamentous bacteria (Merlo et al, 2007).

As with almost all studies of permeability decline in MBRs, the few studies of membrane thickening of WAS have tended to be focused on characterisation of chemical foulants. However, it is broadly recognised by both the practitioner community (Stone and Livingston, 2008; Santos et al, 2010; Mason et al, 2010;) and, increasingly, by the academic community (Lebegue et al, 2009; Dvořák et al, 2011; Buzatu et al, 2012; Gabarrón et al, 2013) that clogging - the accumulation of solids within the membrane interstices (or spaces between the fibres) - represents as significant challenge to sustainable MBR operation as membrane surface fouling. Since clogging propensity would be expected to be greater at elevated sludge concentrations, it is of obvious importance to assess the relative significance of fouling and clogging in such cases.

The purpose of this study was to establish the impact on filtration behaviour in a standard HF iMBR on changing biological treatment from low to high solids concentration, the latter being normally associated with thickening, based on normal operating conditions. Determinants studied included bulk sludge quality parameters (normalised CST and diluted sludge volume index, DSVI), standard foulant indicators (filtered COD, SMP and extracellular polymeric substances, EPS) and clogging propensity (expressed as accumulated solids per $\mathrm{m}^{2}$ membrane area). The clogging propensity may then be correlated both with the sludge quality and the operational flux.

\section{Material and Methods}

\subsection{Feed water and chemicals}

The feedwater comprised settled sewage from the Cranfield University wastewater treatment works, which had predominantly typical municipal wastewater characteristics and varied little in quality throughout the trials (Table 1). This stream was supplemented with molasses (Algerian Refinery Cane sugar, British Sugar), which was revealed from laboratory analysis to provide $1.14 \mathrm{~kg} \mathrm{COD} / \mathrm{L}$. The stock molasses solution was diluted by 40 times with water to provide a pumpable solution held in a make-up tank. This make-up solution was prepared twice weekly and used to deliver the carbon load required to meet the target F:M ratio of 0.13 
$\mathrm{d}^{-1}$ (Table 2). All other chemicals associated with pilot plant operation (such as sodium hypochlorite for membrane cleaning) were of general purpose grade.

\subsection{Pilot plant}

The pilot-scale membrane bioreactor installation (Fig. 1) comprised a biotank ( $5 \mathrm{~m}^{3}$ volume) and a membrane tank $\left(1.75 \mathrm{~m}^{3}\right)$. The biotank (Forbes, Scotland) base was fitted with 16 fine bubble diffuser aerators (FBDA) (EDI Flexair T-series, USA) supplied with compressed air to provide a dissolved oxygen (DO) concentration of 1-2 $\mathrm{mg} \mathrm{L}^{-1}$. Sludge from the biological process tank was delivered to the membrane tank via a progressive cavity pump (Mono, Model C14AC10RMA, England), overflowing back into the process tank under gravity. Two other pumps (Watson Marlow, Model 520 Du, England) were cascade-connected to deliver the diluted molasses make-up solution into the biotank. The DO data was monitored online using a DO sensor fitted in the biotank, along with sensors for total suspended solids (TSS) and temperature (Hach, USA).

Table 1: Influent water quality for the different target MLSS concentrations campaigns with standard deviation (S.D.) values (from 44-132 measurements)

\begin{tabular}{|c|c|c|c|}
\hline Target MLSS: & $8 g L^{-I}$ & $20 \mathrm{gL}^{-1}$ & $32 g^{-1}$ \\
\hline TSS, g L L (S.D.) & $0.2(66 \%)$ & $0.09(13 \%)$ & $0.22(72 \%)$ \\
\hline Turbidity, NTU (S.D.) & - & $72(13 \%)$ & $107(60 \%)$ \\
\hline VSS, g L L $^{-1}$ (S.D.) & $0.18(68 \%)$ & $0.08(13 \%)$ & $0.19(71 \%)$ \\
\hline $\begin{array}{l}\text { TCOD, } \text { mg L L }^{-1} \text { (S.D.) } \\
\text { SCOD, } \text { mg L L }^{-1} \text { (S.D.) } \\
\text { BOD, mg L }\end{array}$ & $\begin{array}{l}379(56 \%) \\
73.8(25 \%) \\
90(136 \%)\end{array}$ & $\begin{array}{l}337(7 \%) \\
91(21 \%) \\
65(0 \%)\end{array}$ & $\begin{array}{l}484(48 \%) \\
134(34 \%) \\
92.8(109 \%)\end{array}$ \\
\hline pH (S.D.) & $8.3(6 \%)$ & $8.6(3 \%)$ & $8.3(4 \%)$ \\
\hline \multicolumn{4}{|l|}{ Nutrients, $\operatorname{mg~L}^{-1}(\mathrm{SD})$ : } \\
\hline 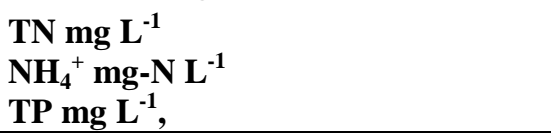 & $\begin{array}{l}44(20 \%) \\
24(42 \%) \\
7.6(31 \%)\end{array}$ & $\begin{array}{l}48(20 \%) \\
31(10 \%) \\
7.2(14 \%)\end{array}$ & $\begin{array}{l}44.6(16 \%) \\
30.5(21 \%) \\
7.9(29 \%)\end{array}$ \\
\hline
\end{tabular}

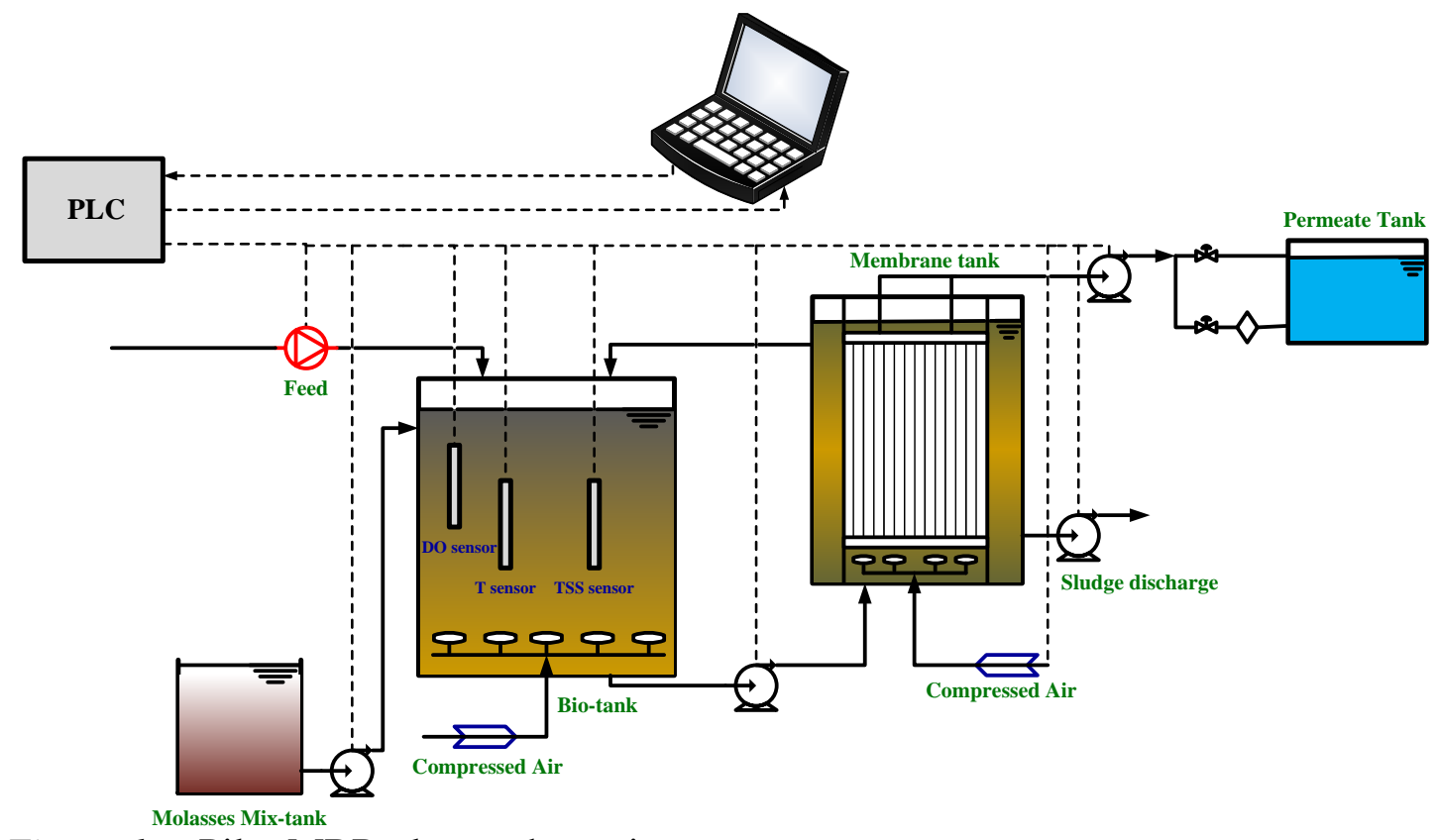

Figure 1: Pilot MBR plant, schematic 
Table 2: $\quad$ MBR operation conditions

\begin{tabular}{|c|c|c|c|c|}
\hline \multirow[t]{2}{*}{ Parameters } & \multirow[t]{2}{*}{ Unit } & \multicolumn{3}{|c|}{ Operational periods } \\
\hline & & Low MLSS & Thickening & High MLSS \\
\hline SRT & Days & $38 \pm 4$ & $47-90$ & $47 \pm 1$ \\
\hline HRT & Hours & $7.9 \pm 0.5$ & $7.8-22.7$ & $21.8 \pm 0.9$ \\
\hline VLR & $\mathrm{kgCOD} \mathrm{m}^{-3}$ day $^{-1}$ & $1.18 \pm 0.48$ & $0.80-5.59$ & $4.23 \pm 0.43$ \\
\hline F/M & $\mathrm{g} \mathrm{COD} \mathrm{gMLSS}^{-1} \mathrm{day}^{-1}$ & 0.13 & 0.13 & 0.13 \\
\hline $\mathbf{Y}_{\mathrm{H}}$ & $\mathrm{kgMLVSS} \mathrm{kgCOD}^{-1}$ day $^{-}$ & $0.26 \pm 0.15$ & $0.03-0.18$ & $0.13 \pm 0.02$ \\
\hline Air flow rate & $\mathrm{m}^{3} \mathrm{~h}^{-1}$ & 16 & $16-220$ & 220 \\
\hline
\end{tabular}

The open-top rectangular ( $870 \times 420 \times 2800 \mathrm{~mm}$ high) membrane tank was fitted with two vertically-oriented hollow fibre (HF), $0.04 \mu \mathrm{m}$ pore size, polyvinylidene difluoride (PVDF) membrane modules (GE Water \& Process Technologies, Hungary) providing a total membrane area of $46.4 \mathrm{~m}^{2}$. These were mounted in a custom-built skid $(2152 \mathrm{~mm}$ high $\mathrm{x} 307$ $\mathrm{mm} \times 817 \mathrm{~mm}$ ) and operated via a dedicated peristaltic pump (Watson Marlow, Model $720 \mathrm{Du}$, England) providing both filtration and backflush fluxes. The membrane surface was scoured intermittently (10s-on/10s-off) by coarse-bubble aerators, placed $100 \mathrm{~mm}$ below the membrane module channels, which were integrated into the cassette. The membrane, of permeability $375 \mathrm{LMH} \mathrm{bar}^{-1}$ in its virgin state, was backflushed for 30s every 10-minute filtration cycle at a flux of $15 \mathrm{LMH}$. A CEB with $500 \mathrm{mg} \mathrm{L}^{-1}$ sodium hypochlorite and manual declogging (using a low-pressure water stream) were periodically performed to maintain membrane permeability.

A programmable logic controller (PLC) and supervisory control and data acquisition (SCADA) system collecting digital/analogical data, provided by Debaru Kft., Hungary were used to control feed, recirculation, permeate, membrane aeration and waste sludge discharge flows. A pressure sensor was fitted in the biotank for controlling the sludge level. The transmembrane pressure (TMP), permeate and backflush flows were recorded every 30s by an immersed pressure transducer and ultrasonic flowmeters connected to the SCADA system.

\subsection{Flux-step trials}

The short-term flux-step trial (Table 3) comprised four one-hour flux steps incorporating six backflush steps (Zsirai et al, 2012, 2013) whose values were adjusted according to the sludge concentration. The one-hour flux step tests were followed by four extended (18-hour) overnight flux steps. All tests were performed under standard conditions of intermittent aeration (Table 2) and with an intermediate CEB. The TMP and flow response was continuously monitored at a rate of two readings per minute. Flux was corrected from operational (instantaneous) to net flux from a consideration of backflushing (Zsirai et al., 2012) and for temperature using the standard viscosity correction.

Key parameters generated from the TMP and flow data comprised:

- mean permeability $L$ for a given period:

$$
L=0.5\left(\frac{J_{1}}{T M P_{1}}+\frac{J_{2}}{T M P_{2}}\right) \mathrm{LMH} \operatorname{bar}^{-1}
$$

where $J_{1}$ and $J_{2}$ are the initial and final flux values and $T M P_{1}$ and $T M P_{2}$ the corresponding transmembrane pressure values;

- sludge solids loading rate per unit membrane area: 


$$
M_{L}=\operatorname{MLSS} \times \mathrm{g} \mathrm{m}^{-2} \mathrm{~h}^{-1} \text {; and }
$$

- accumulated (clogged) solids loading rate per unit membrane area:

$$
M_{C}=\mathrm{M} / t \quad \mathrm{~g} \mathrm{~m}^{-2} \mathrm{~h}^{-1},
$$

where $\mathrm{M}$ is the gravimetrically measured clogged solids per unit membrane area and $t$ is the time over which the solids have accumulated.

\begin{tabular}{|c|c|}
\hline Parameter & Value \\
\hline Biological process & \\
\hline Sludge temperature range, ${ }^{\circ} \mathrm{C}$ & $7-20{ }^{\circ} \mathrm{C}$ \\
\hline Process air flow & $10-310 \mathrm{~m}^{3} \mathrm{hr}^{-1}$ \\
\hline $\begin{array}{l}\text { Dissolved oxygen concentration, mg } \\
\mathrm{L}^{-1}\end{array}$ & $1-2 \mathrm{mg} \mathrm{L}^{-1}$ \\
\hline Membrane filtration & \\
\hline Flux step range (net, corrected to $20^{\circ} \mathrm{C}$ ) & \\
\hline$-8 \mathrm{~g} \mathrm{~L}^{-1} \mathrm{MLSS}$ & 15-27.5 LMH \\
\hline$-20 \mathrm{~g} \mathrm{~L}^{-1} \mathrm{MLSS}$ & 9.5-15.5 LMH \\
\hline$-32 \mathrm{~g} \mathrm{~L}^{-1} \mathrm{MLSS}$ & 6.1-10 LMH \\
\hline $\mathrm{SAD}_{\mathrm{m}}$ & $0.25 \mathrm{Nm}^{3} \mathrm{~h}^{-1} \mathrm{~m}^{-2}, 10 \mathrm{~s}$ on, $10 \mathrm{~s}$ off \\
\hline Filtration mode & $9.5 \mathrm{~min}$ suction / $0.5 \mathrm{~min}$ backwash at a flux of $15 \mathrm{LMH}$ \\
\hline Total step length & $1 \mathrm{hr}$ short-term; $18 \mathrm{hr}$ long-term \\
\hline
\end{tabular}

Table 3: Test conditions

\subsection{Declogging and chemical cleaning}

Retained sludge solids were determined gravimetrically by difference using a $100 \mathrm{~g}$ resolution load cell (Straightpoint miniweighter, Havant, UK) fitted to the membrane cassette. The module was removed following each test and the residual liquid allowed to drain for one hour. The entrained sludge solids were then carefully removed from within the fibre bundles using a low-pressure water hose and the cassette re-weighed after draining. This was then followed by chemical cleaning. Chemical cleaning comprised cycles of CEB at 15 LMH using $500 \mathrm{mg} \mathrm{L}^{-1} \mathrm{NaOCl}$ applied for 15 pulses of 30 seconds each with 2 minutes relaxation between the pulses, as recommended for this product. Prior to the trials the sludge was allowed to acclimatize for a period of a month.

Other analyses

Standard feed, permeate and sludge quality data were recorded daily to twice-weekly. Feed and permeate water quality comprised the standard sanitary determinants along with conventional bulk sludge quality parameters (diluted sludge volume index, DSVI, and normalised capillary suction time, nCST) and standard foulant indicators (soluble microbial product, SMP, and extracellular polymeric substances, EPS). SMP and EPS were determined according to established heat extraction methodology (Le Clech et al, 2003), and bulk sludge quality by standard methods (APHA, 2005). The particle size diameter (PSD) was also determined using a Malvern Mastersizer instrument (Malvern 2000, Worcestershire, UK) with the measurement range of 0.1-1000 $\mu \mathrm{m}$. 


\subsection{Trials}

Trials conducted comprised:

- Steady-state operation at three different target MLSS concentrations (8, 20 and $32 \mathrm{~g}$ $\mathrm{L}^{-1}$ )

- Thickening trials (from 8 to 32 and from 20 to $32 \mathrm{~g} \mathrm{~L}^{-1}$ )

Flux step experiments (Section 2.3) were carried out following steady operation for at least 30 days. CEB and declogging was conducted at the completion of each thickening trial and between each flux step test.

For the first thickening trial the sludge concentration was increased from $8.7 \mathrm{~g} \mathrm{~L}^{-1}$ to a target concentration of $37 \mathrm{~g} \mathrm{~L}^{-1}$ over a period of 58 days. The solids concentration was then reduced by wasting and the trial repeated for solids concentrations between $20 \mathrm{~g} \mathrm{~L}^{-1}$ and $32 \mathrm{~g} \mathrm{~L}^{-1}$, following chemical cleaning and declogging of the membrane. Thickening was conducted at a loading of 2-4 $\mathrm{kg} \mathrm{COD} \mathrm{m}^{-3}$ day $^{-1}$ through a combination of the municipal wastewater feed (480 $\mathrm{mg} \mathrm{L}^{-1}$ on average) with the molasses solution, maintaining the $\mathrm{F}: \mathrm{M}$ ratio at $\sim 0.13 \mathrm{~d}^{-1}$. The resulting rate of increase in MLSS was around $0.5 \mathrm{~g} \mathrm{MLSS} \mathrm{L}^{-1} \mathrm{~d}^{-1}$. Throughout the thickening trial the flux was manually adjusted so as to maintain a TMP below 50 mbar, this then being regarded as the "sustainable" flux.

\section{Results}

\subsection{Permeate and sludge quality}

Permeate quality throughout the trials was routinely high with respect to ammonia, BOD and suspended solids removal, all being close to $100 \%$. Permeate COD levels were more variable as a consequence of SMP and EPS generation in the bioreactor, as determined from sampled sludge during steady-state operation (Table 4), with COD removals averaging 91\% (S.D. 8\%) throughout of the study. For such steady-state operation the SMP concentration, nCST and the SCOD in the bioreactor value varied roughly in accordance with the VSS concentration. However, the normalised EPS concentration did not demonstrate the same trend. The increased SMP and EPS levels manifested during the thickening period subsided to some extent during the equilibrations periods

The sludge normalised DSVI was largely unchanged across all three solids concentrations despite the 50-60\% reduction in mean particle size at the higher MLSS levels brought about by the more vigorous aeration demanded to maintain the target DO concentration (Table 4). It is well known that floc breakage leads to increased SMP and EPS levels, possible leading to increased fouling propensity (Chabaliná et al., 2012). Biomass quality monitored during thickening otherwise indicated a predictably large increase in both (nCST), from 1.4 to $\sim 5 \mathrm{~s} \mathrm{~L}$ $\mathrm{g}^{-1}$, and sCOD from 60 to $>500 \mathrm{mg} \mathrm{L}^{-1}$ (Fig. 2) as compared to corresponding values of 4-4.8 $\mathrm{s} \mathrm{L} \mathrm{g}^{-1}$ and $300 \mathrm{mg} \mathrm{L}^{-1}$ respectively recorded by Wang et al. (2006) at $25 \mathrm{~g} \mathrm{~L}^{-1}$ MLSS. These authors similarly reported rapid increases in nCST and sCOD, along with less marked increases in EPS and viscosity, during their thickening trials. The nCST of the sludge remained low $\left(<0.45 \mathrm{~s} \mathrm{~L} \mathrm{~g}^{-1}\right)$ for biomass concentrations below 20-22 $\mathrm{g} \mathrm{L}^{-1}$ then rapidly increased beyond $22 \mathrm{~g} \mathrm{~L}^{-1}$, suggesting that filterability diminishes when solids concentration exceeds some threshold value - corroborating previously reports (Pollice et al., 2007). 
Table 4: Sludge quality under steady-state conditions for given target MLSS concentrations, in chronological order, with standard deviation (S.D.) values

\begin{tabular}{|c|c|c|c|}
\hline Parameter & $8 g L^{-1} M L S S$ & $20 g L^{-1} M L S S$ & $32 \mathrm{gL}^{-1} M L S S$ \\
\hline TSS (S.D.), VSS (S.D.), g L & $8.9(17 \%), 6.9(19 \%)$ & $21(3 \%), 15(1 \%)$ & $32(0.5 \%), 27(4.3 \%)$ \\
\hline VSS/TSS & $78 \%$ & $71 \%$ & $83 \%$ \\
\hline EPS (S.D.), SMP (S.D.), $\mathrm{mg} \mathrm{L}^{-1}$ & $603(13 \%), 18.9(17 \%)$ & $1100(5 \%), 54(4 \%)$ & $1600(3.8 \%), 130(20 \%)$ \\
\hline nEPS, nSMP, g L L $^{-1}$ VSS $^{-1}$ & $34,2.7$ & $73,3.6$ & $59,4.8$ \\
\hline $\begin{array}{l}\text { nCST (S.D.), s L } \mathrm{g}^{-1} \text {, nDSVI (S.D.), } \\
\mathrm{ml} / \mathrm{g}\end{array}$ & $1.4(40 \%), 108(18 \%)$ & $1.6(11 \%), 110(15 \%)$ & $4(20 \%), 140(6 \%)$ \\
\hline sCOD (S.D.), $\mathrm{mg} \mathrm{L}^{-1} \mathbf{d}_{50}$ (S.D.), $\mu \mathrm{m}$ & $77(37 \%), 89(215 \%)$ & & $430(18 \%), 36(1.4 \%)$ \\
\hline pH (S.D.), T (S.D.), ${ }^{\circ} \mathrm{C}$ & $7.3(4.4 \%), 11(11 \%)$ & $8.2(1.2 \%), 7.4(13 \%)$ & $8(1.2 \%), 7.4(13 \%)$ \\
\hline
\end{tabular}

TSS, VSS total, volatile suspended solids; EPS extracellular polymeric substances; SMP soluble microbial product; $\mathrm{n}$ normalised against VSS concentration; $\mathrm{nCST}$ capillary suction time; $\mathrm{nDSVI}$ diluted sludge volume index, normalised to TSS; sCOD soluble chemical oxygen demand; $\mathrm{d}_{50}$ mean particle diameter.

\subsection{Permeability trends}

\subsubsection{Low MLSS trial}

Flux step trials conducted initially for the membrane conditioned for one month at a mean MLSS concentration of $8.9 \mathrm{~g} \mathrm{~L}^{-1}$, following three months of operation at a mean MLSS of 7.3 $\mathrm{g} \mathrm{L}^{-1}$, revealed operation to be free from clogging $\left(<2 \mathrm{~g} \mathrm{~m}^{-2}\right.$ membrane area, the limit of detection for clogged solids area concentration), requiring no CEB, even at the highest applied flux of $28 \mathrm{LMH}$. The mean permeability - with a measured S.D. of $\sim 20 \%$ - decreased marginally from 380 at $15 \mathrm{LMH}$ to $340 \mathrm{LMH} /$ bar at $27.5 \mathrm{LMH}$, with no measurable fouling rate over the course of either the $1 \mathrm{~h}$ or $18 \mathrm{~h}$ flux step trials. The backflush cycle under these conditions was found to maintain the permeability without recourse to a CEB.

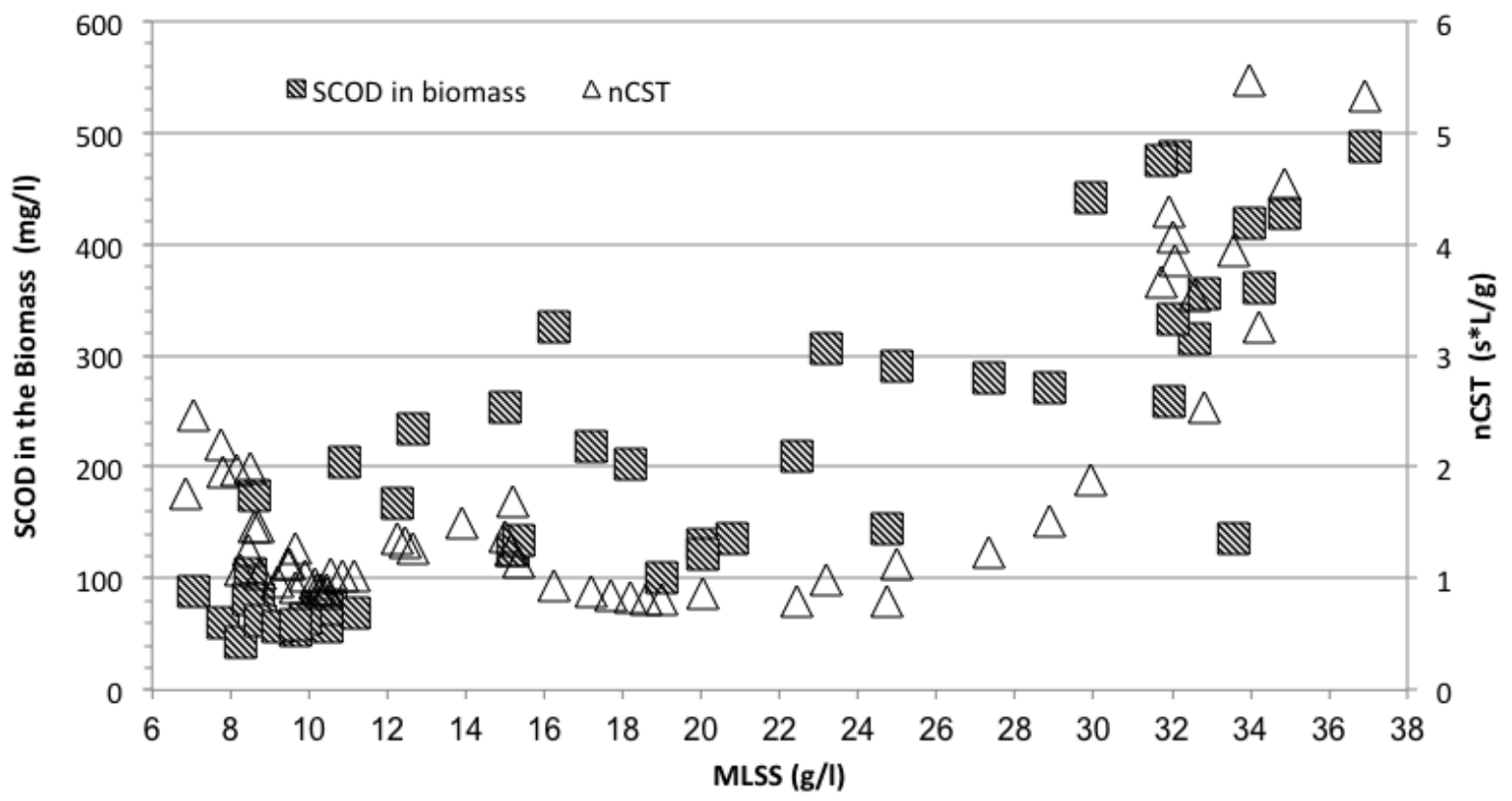

Figure 2: $\quad \mathrm{nCST}$ and sCOD against MLSS concentration, first thickening trial

\subsubsection{Thickening trials and critical flux trial}

Prior to the first thickening trial the permeability decrease between 8 and $18 \mathrm{~g} \mathrm{~L}^{-1}$ was marginal (400-350 LMH/bar) and the corrected flux was maintained at 22-24 LMH. Thickening beyond an MLSS concentration of around $18 \mathrm{~g} \mathrm{~L}^{-1}$ resulted in the first 
pronounced decline in sustainable flux and permeability (Fig. 3a and b) due to the channel clogging ("pre-clogged" state), with values noticeably depressed (by 25-50\%) for the duplicated trial ("post-clogged" state). The trend is similar to that reported by Wu et al. (2009) in their studies of an FS iMBR for membrane-based simultaneous sludge thickening and aerobic digestion of activated sludge. These authors reported thickening of the sludge from 5-35 $\mathrm{g} \mathrm{L}^{-1}$ MLSS to decrease the operational flux from 30 to $10 \mathrm{LMH}$. Robles et al. (2013) also reported significantly depressed permeability values (to between 50 and 100 $\mathrm{LMH} /$ bar) for an immersed anaerobic HF MBR operating between 26 and $32 \mathrm{~g} \mathrm{~L}^{-1}$.

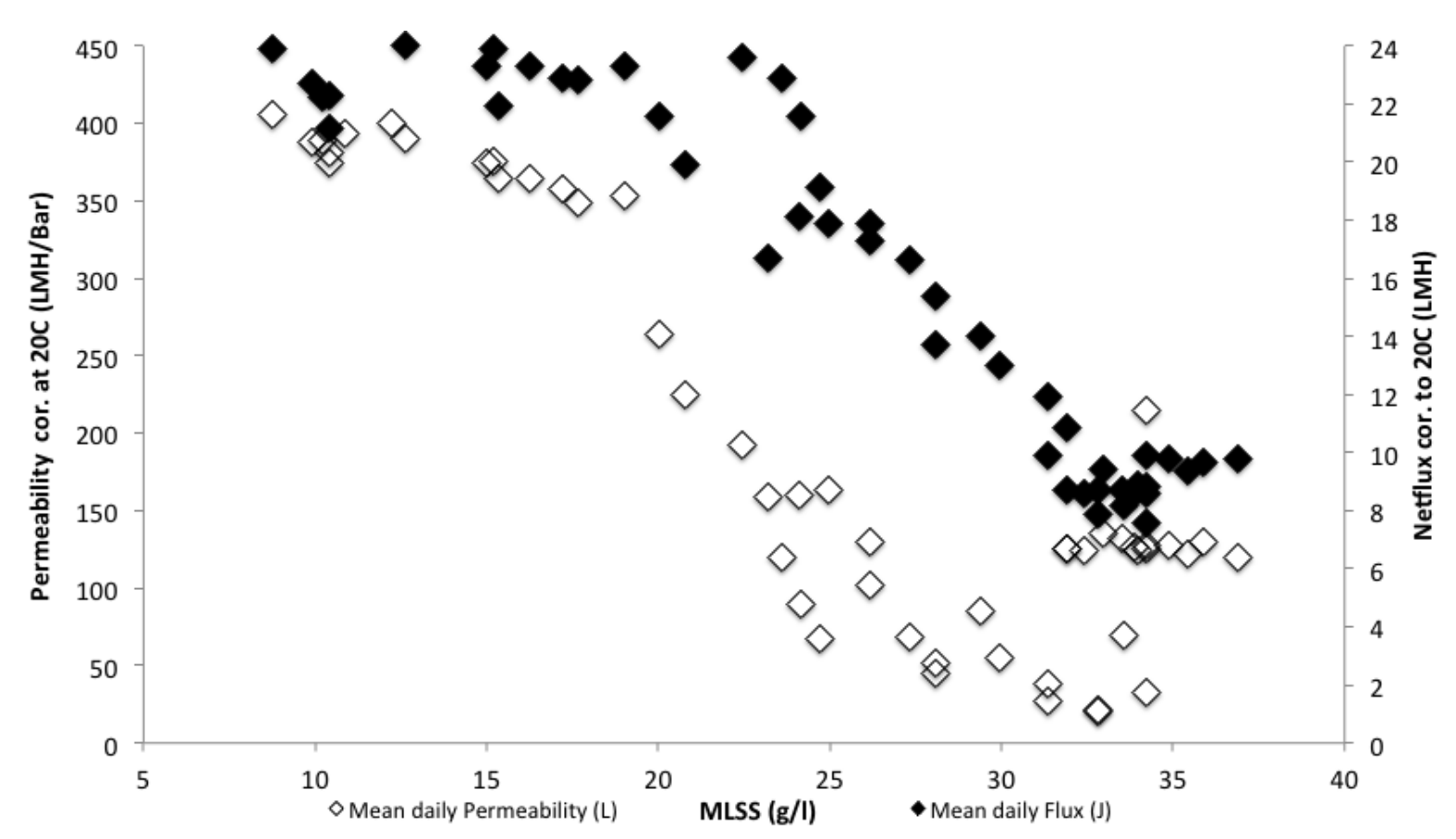

(a)

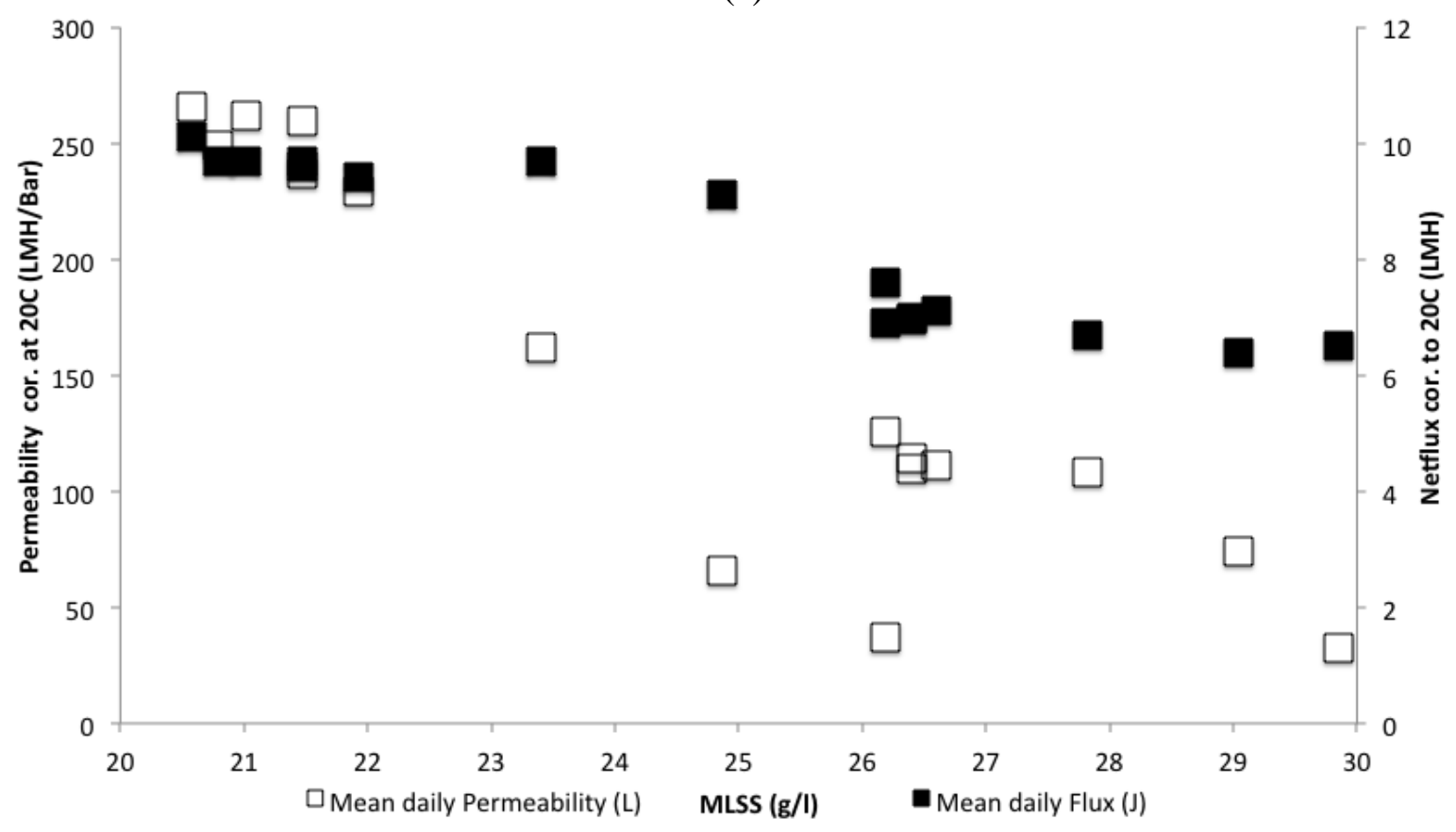

(b)

Figure 3: Impact of MLSS on mean daily net flux (filled) and permeability (open) (corrected to $20^{\circ} \mathrm{C}$ ) (a) preclogging and (b) post clogging. 
Whereas both irreversible fouling and clogging were absent at the lowest MLSS, the membranes required declogging supplemented with regular CEBs at the higher solids concentrations. The CEB was only effective (110\% permeability recovery for the pre-clogged and $97 \%$ for the post-clogged membrane) at the lowest applied flux (6.8-7.2 LMH for the pre-clogged and 4.3-5.2 LMH for the post-clogged membrane), prior to the onset of clogging or reclogging. Beyond some flux threshold only declogging was effective in recovering permeability, with recovery from CEB becoming negligible. Clogging propensity (Section 3.3) was observed to become extremely sensitive to flux at the highest MLSS values.

\subsection{High-MLSS trials}

Duplicate one-hour flux-step trials performed at an MLSS concentration of $\sim 32 \mathrm{~g} \mathrm{~L}^{-1}$ revealed the permeability range to decrease from $178 \mathrm{LMH} \mathrm{bar}^{-1}$ (S.D. 19\%) to $139 \mathrm{LMH}$ $\operatorname{bar}^{-1}$ (S.D. 13\%) over a flux step range of 7.5-11 LMH. Data indicate a 25-30\% decrease in permeability between the two trials, notwithstanding the declogging and CEB applied following the first trial. Similarly, the $18 \mathrm{~h}$ flux-step data, obtained for a lower flux step range of 6-10 LMH (Fig 4), indicated a higher fouling rate for the post-clogged membrane than the preclogged one. Permeability decreased linearly with flux, similar to the low-MLSS trends, but $18 \mathrm{~h}$ operation could not be sustained at fluxes above $10 \mathrm{LMH}$ for the preclogged membrane and 8.2 LMH for the post-clogged (and declogged) one.

\subsection{Clogging and declogging}

Trials were conducted at more extended run times of 7-10 days to attempt to establish the clogging propensity of the membrane in the MLSS concentration range between 22 and $35 \mathrm{~g}$ $\mathrm{L}^{-1}$. Measured accumulated solids levels varied between 140 and $1160 \mathrm{~g} \mathrm{~m}^{-2}$ membrane area depending on the operating conditions of flux and MLSS concentration. Correlations for both flux against MLSS (Fig. 5) and solids accumulation rate $M_{C}$ against solids loading rate $M_{L}$ (Section 2.3) for both the pre-clogged and post-clogged membrane (Fig. 6), where the latter had been declogged and chemically cleaned (Section 2.4) prior to testing, indicate that:

There is an approximately linear decrease in sustainable flux with MLSS between 25 and 35 LMH for the pre-clogged membrane: the sustainable flux for the post-clogged membrane is $30-50 \%$ lower than that of the pre-clogged membrane at the two reference data points at 22.5 and $27.5 \mathrm{~g} \mathrm{~L}^{-1}$ (Fig. 5).

There is an approximately linear increase in accumulated solids with MLSS under the above operating conditions for the pre-clogged membrane, with the clogging propensity for the post-clogged membrane being about double that of the pre-clogged membrane according to the two MLSS data points at 22.5 and $27.5 \mathrm{~g} \mathrm{~L}^{-1}$ (Fig. 6). Data for a single $18 \mathrm{~h}$ trial revealed a linear relationship between solids accumulation and solids loading (Fig. 6, inset).

There was a marked sensitivity of clogging to flux, particularly at the highest MLSS concentration. An increase from 7 to $8 \mathrm{LMH}$ resulted in a $40 \%$ increase in retained solids per $\mathrm{m}^{2}$ membrane area. For an accumulated wet solids concentration exceeding $\sim 700 \mathrm{~g} \mathrm{~m}^{-2}$ the flux became unsustainable regardless of the MLSS concentration, leading to further rapid clogging. Similar qualitative impacts of MLSS on sustainable flux have been reported previously (Schwarz et al, 2006), though these refer to lower MLSS concentrations. 


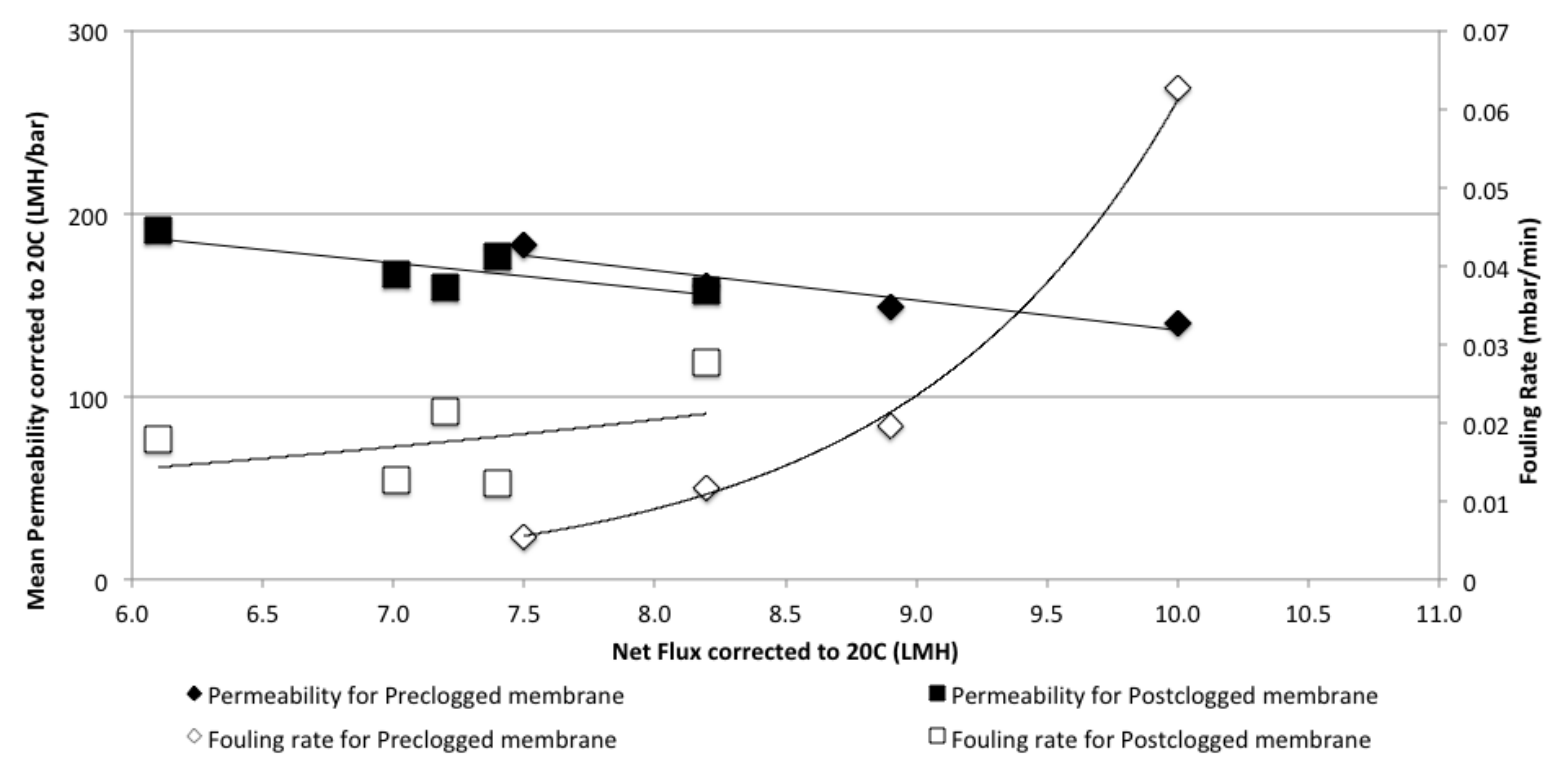

Figure 4: Mean permeability (filled data points) and fouling rate (open) against net flux corrected to $20^{\circ} \mathrm{C}$ for preclogged and post-clogged membrane, $\sim 32 \mathrm{~g} \mathrm{~L}^{-1}$ MLSS.

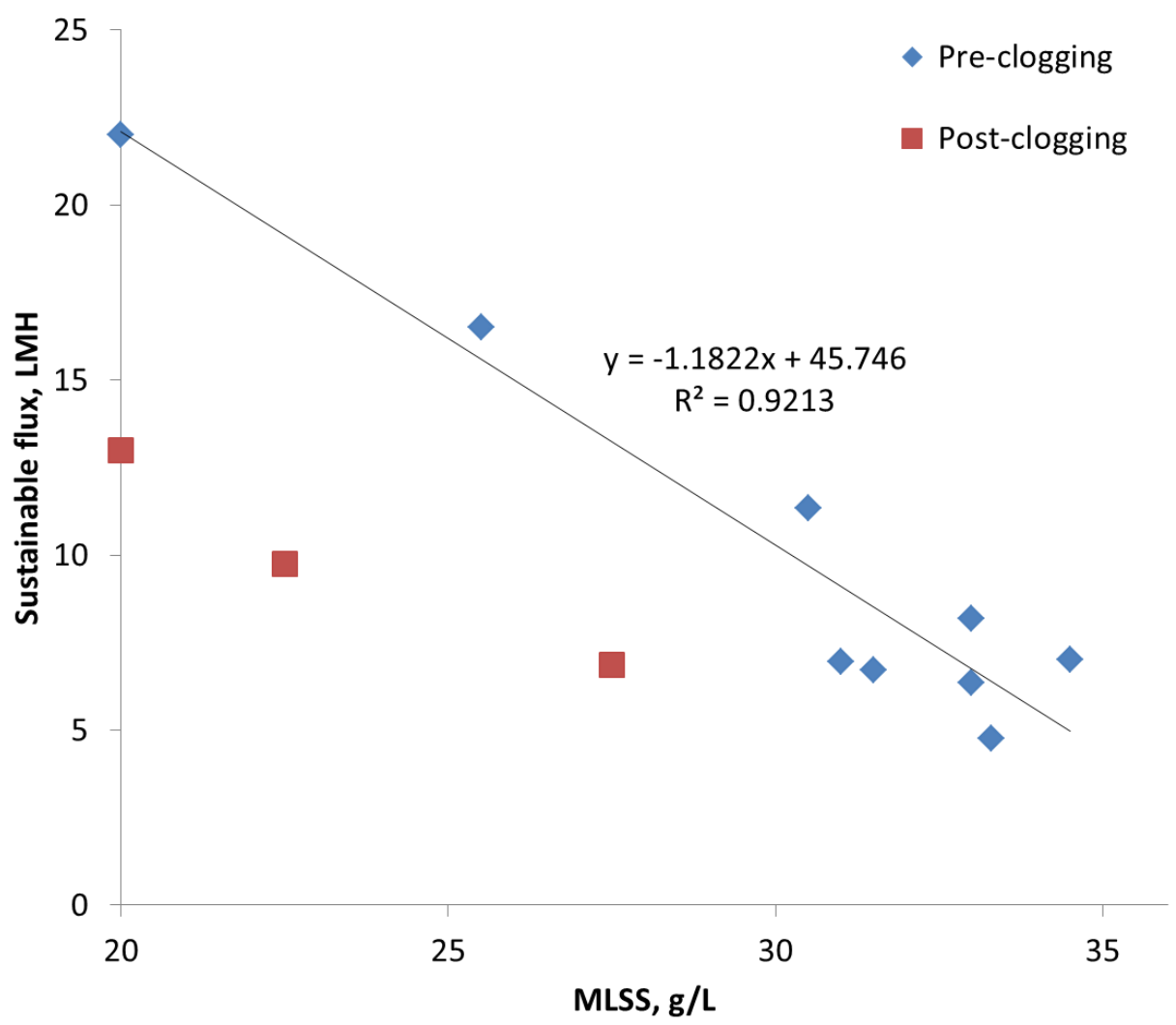

Figure 5: Flux vs. MLSS concentration, 7-10 day operational data, pre-clogged and postclogged membrane, $\sim 32 \mathrm{~g} \mathrm{~L}^{-1}$ MLSS 


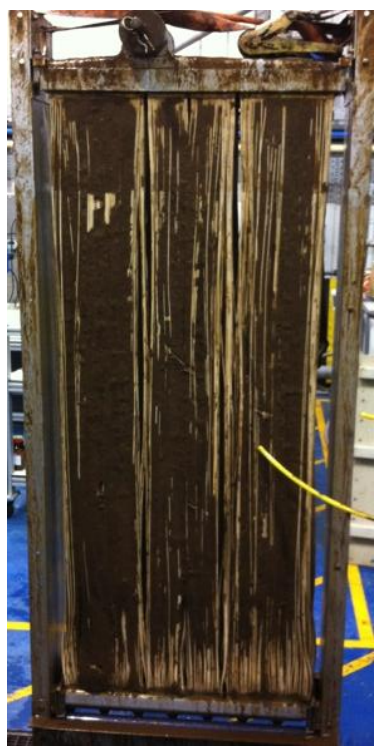

(a)

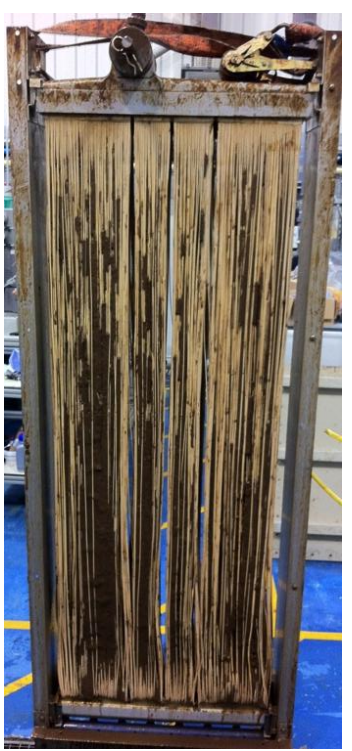

(b)

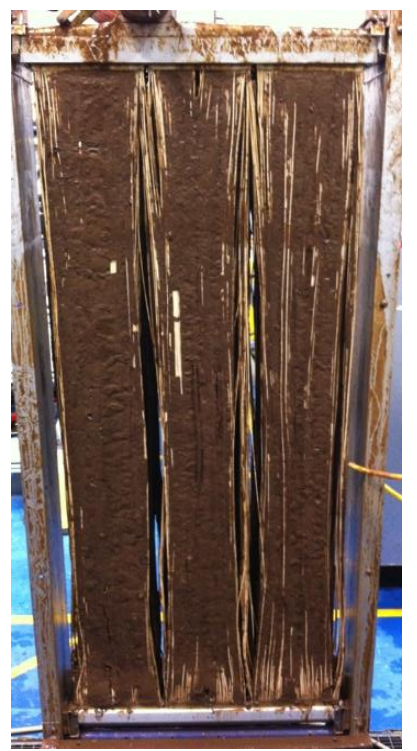

(c)

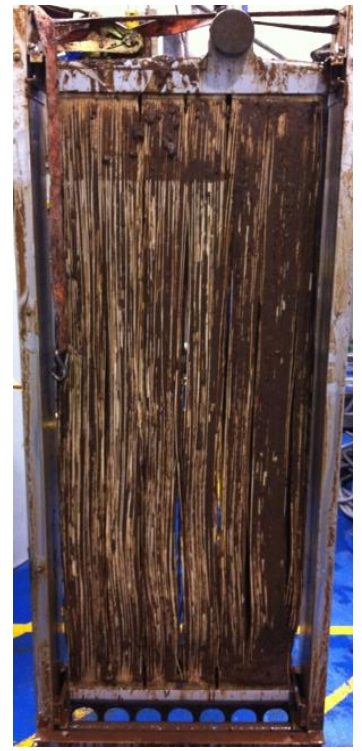

(d)

Figure 6: Sludge solids accumulation after 7-10 days at (a) $32 \mathrm{~g} \mathrm{~L}^{-1}$ and (b) 20-22 $\mathrm{g} \mathrm{L}^{-1}$ for the pre-clogged membrane, and at (c) $32 \mathrm{~g} \mathrm{~L}^{-1}$ and (d) $22 \mathrm{~g} \mathrm{~L}^{-1}$ for the postclogged membrane

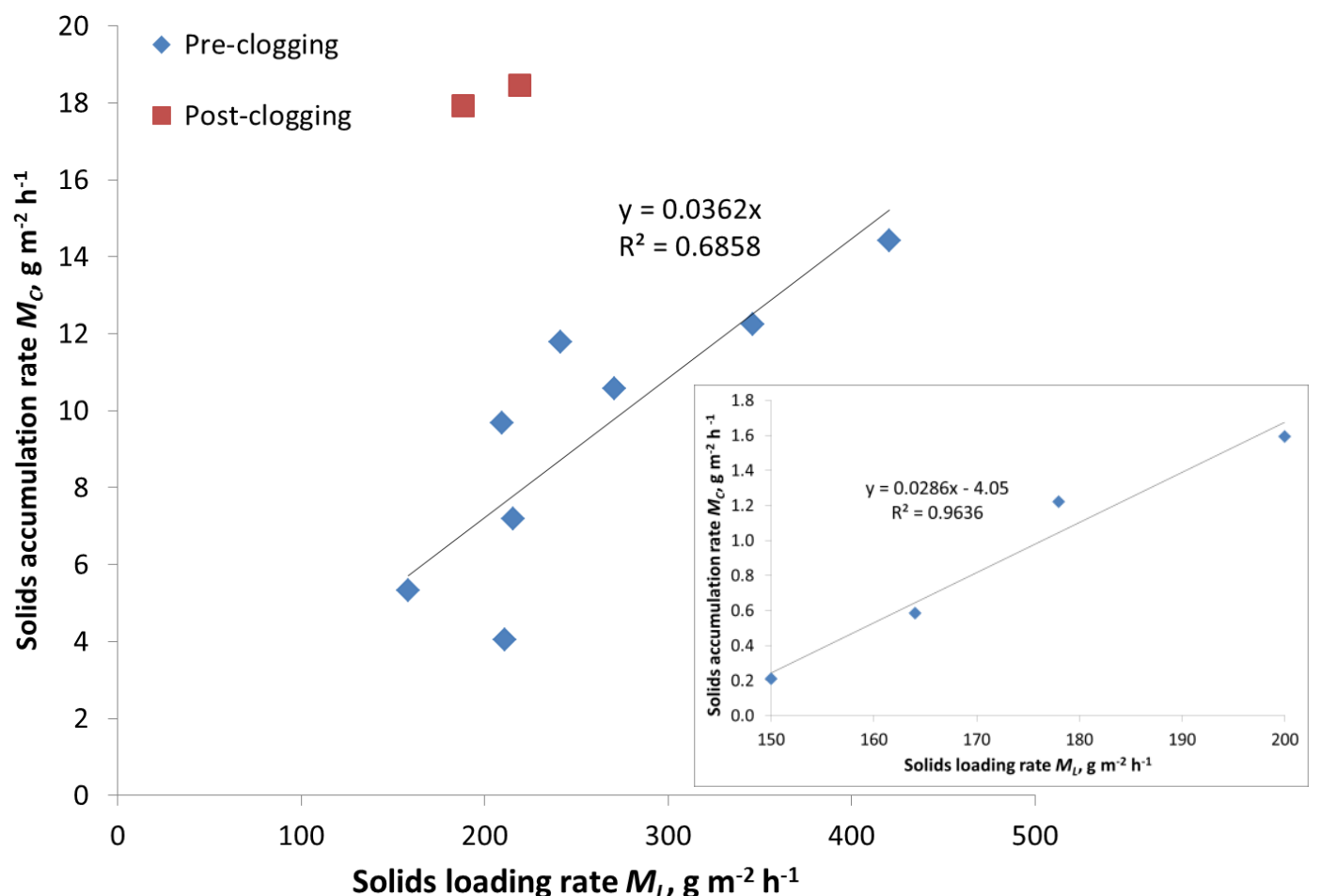

Figure 7: Sludge solids accumulation vs. loading, 7-10 day operational data, pre-clogged and post-clogged membrane. Inset: equivalent data for $18 \mathrm{~h}$ operation at $20 \mathrm{~g} \mathrm{~L}^{-1}$ MLSS

The observed impact of clogged solids on permeability of the subsequently cleaned membrane corroborates outcomes from a previous study (Buzatu et al, 2012), as well as field observations (Gabarrón et al, 2013), in that the deleterious impact of clogging on membrane permeability is retained even after declogging and cleaning. A repeat of the trial following declogging and a subsequent aggressive CEB at a very high hypochlorite concentration of 
$3000 \mathrm{mg} \mathrm{L}^{-1} \mathrm{NaOCl}$ did not significantly recover the membrane permeability over an extended term. This is assumed to be indicative of irreversible pore plugging (Kimura et al, 2013; Shen et al, 2010).

\section{Conclusions}

The outcomes of a study of a pilot-scale MBR fed with fortified sewage to maintain a moderate F:M ratio (of $0.13 \mathrm{~d}^{-1}$ ) whilst operating at high MLSS concentrations have revealed significant deleterious impacts above solids concentrations of $18 \mathrm{~g} \mathrm{~L}^{-1}$. Sustainable flux was found to depend as much on membrane condition as on sludge concentration. Clogging of the membrane compromises its subsequent performance both with respect to its permeability and further clogging propensity, notwithstanding the extent of declogging and chemical cleaning imparted to the membrane following initial clogging. In both cases the performance of the post-clogged membrane is around half that of the preclogged one, with solids accumulation (or clogging propensity) doubling and permeability from fouling decreasing by $30-50 \%$.

Solids appear to accumulate roughly linearly with flux above some critical threshold flux, the value of which rapidly decreases with sludge concentration above MLSS levels of $\sim 18 \mathrm{~g} \mathrm{~L}^{-1}$. Longer-term trials of 7-10 days suggest that, over this time period, around 3\% of the sludge solids loaded onto the membrane are retained within the membrane fibres. Chemicallyenhanced backflushing (CEB) is only effective in recovering permeability at relatively low clogged solids levels of $\sim 600-800 \mathrm{~g}$ per $\mathrm{m}^{2}$ membrane area. Outcomes confirm the importance of sustainable flux operation across MBR technologies generally, and the importance of avoiding clogging.

\section{Acknowledgements}

The authors gratefully acknowledge the support of Praxair Inc., USA, who funded this work, and GE Water and Process Technologies, Hungary, who provided the membrane modules.

\section{References}

APHA (2005), American Public Health Association, American Water Works Association (AWWA) \& Water Environment Federation (WEF): Standard Methods for the Examination of Water and Wastewater, 21st Edition.

Buzatu, P., Zsirai, T., Aerts, P., and Judd, S.J. (2012). Permeability and clogging in an immersed hollow fibre membrane bioreactor. Journal of Membrane Science 421-422 342348.

Chabaliná, L.D., Ruiz, J.B., Pastor, M.R., Rico, D.P. (2012). Influence of EPS and MLSS concentrations on mixed liquor physical parameters of two membrane bioreactors, Desalination and Water Treatment 46, (1-3) 46-59.

Dvořák, L., Gómez, M., Dvořáková, M., Růžičková, I., and Wanner, J. (2011). The impact of different operating conditions on membrane fouling and EPS production. Bioresource Technology 102 (13) 6870-6875.

Gabarrón, S., Gómez, M., Monclús, H., and Rodríguez-Roda, I., Comas, J. (2013). Ragging phenomenon characterisation and impact in a full-scale MBR. Water Science and Technology 67 (4) 810-816. 
Judd, S, and Judd, C. (2010). The MBR Book, Elsevier, Lon/NY.

Kimura, K., Ogyu, R., Miyoshi, T., Naruse, T., Tsuyuhara, T., and Watanabe, Y. (2013). Membrane fouling caused by sub-micron particles in a mixed liquor suspension of an MBR. Water Science and Technology 67(11) 2602-2607.

Le Clech, P., Jefferson, B., Chang I-S, and Judd, S.J. (2003). Critical flux analysis by the flux step method in a submerged membrane bioreactor, Journal of Membrane Science 227(1-2) 81-93.

Lebegue, J., Heran, M., and Grasmick, A. Membrane air flow rates and HF sludging phenomenon in SMBR (2009). Desalination 236 (1-3) 135-142.

Mason, S., Ewert, J., Ratsey, H., Sears, K., and Beale, J. (2010). Flat sheet membrane bioreactors operational experiences - a New Zealand perspective, in: Proceedings of NZWWA Conference, Christchurch, Canterbury, New Zealand, September 2010.

Merlo, R.P., Trussell, R.S., Hermanowicz, and S.W., Jenkins, D. (2007). Effects of sludge properties on the thickening and dewatering of waste activated sludge, Water Environment Research 79(12) 2412-2419.

Pollice A., Giordano C., Laera G., Saturno D., Miminni G., (2007). Physical characteristics of the sludge in a complete retention membrane bioreactor, Water Research (41) 1832-1840.

Reed, I., Oakley, D., and Dudley, Linda (1993). Separation of activated sludge by ultrafiltration, Institution of Chemical Engineers Symposium Series (132) 147-153.

Robles, A., Ruano, M.V., Ribes, J., Ferrer, J. (2013). Factors that affect the permeability of commercial hollow-fibre membranes in a submerged anaerobic MBR (HF-SAnMBR) system, Water Research 47 (3), 1277-1288

Santos, A., Ma., W and Judd, S. J. (2011). Membrane bioreactor technology: two decades of research and implementation, Desalination, 273, 148-154.

Schwarz, A.O., Rittmann, B.E., Crawford, G.V., Klein, A.M., Daigger, G.T. (2006). Critical review on the effects of mixed liquor suspended solids on membrane bioreactor operation, Separation Science and Technology 41, (7) 1489-1511.

Shen, Y., Zhao, W., Xiao, K., and Huang, X. (2010). A systematic insight into fouling propensity of soluble microbial products in membrane bioreactors based on hydrophobic interaction and size exclusion, Journal of Membrane Science 346 (1), 187-193.

Stone, M. and Livingston, D (2008). Flat plate MBR energy consumption - village of Dundee, MI. Membrane Technology 2008 Conference Proceedings of the Water Environment Federation, Alexandria (VA) Jan 27-30.

Trussell, R.S., Merlo, R.P., Hermanowicz, S.W., Jenkins, D. (2007). Influence of mixed liquor properties and aeration intensity on membrane fouling in a submerged membrane bioreactor at high mixed liquor suspended solids concentrations. Water Research 41 (5), 947 958.

Wang Z.-W., Wu Z.-C., Gu G.-W., Yu G.-P., Ma L.-M. (2006). Simultaneous nitrogen and phosphorus removal in an aerobic submerged membrane bioreactor, Journal of Environmental Sciences 18, (3) 439-445.

Wang, X., Wu, Z., Wang, Z., Yin, X., and Du, X. (2009). Floc destruction and its impact on dewatering properties in the process of using flat-sheet membrane for simultaneous thickening and digestion of waste activated sludge. Bioresource Technology 100(6) 19371942. 
Wang, X., Wu, Z., Wang, Z., Du, X., Hua, J. (2008). Membrane fouling mechanisms in the process of using flat-sheet membrane for simultaneous thickening and digestion of activated sludge, Separation and Purification Technology 63(3) 676-683.

Woo, B., (2010). Aerobic Digestion Processes with Membrane Thickening is SOS, OWEA Conference.

Wu, Z., Wang, X., Wang, Z., Du, X. (2009). Identification of sustainable flux in the process of using flat-sheet membrane for simultaneous thickening and digestion of waste activated sludge. Journal of Hazardous Materials 162 (2-3) 1397-1403.

Yeom I.T., Lee K.R., Choi Y.G., Kim H.S., Kwon J.H., Lee U.J., Lee Y.H. (2005). A pilot study on accelerated sludge degradation by a high-concentration membrane bioreactor coupled with sludge pretreatment, Water Science and Technology 52, (10-11) 201-210.

Zsirai, T., Buzatu, P., Aerts, P. and Judd, S.J. (2012). Efficacy of relaxation, backflushing, chemical cleaning and clogging removal for an immersed hollow fibre membrane bioreactor, Water Research 46, (14) 4499-4507.

Zsirai, T., Aerts, P., Judd, S. (2013). Reproducibility and applicability of the flux step test for a hollow fibre membrane bioreactor, Separation and Purification Technology 107, 144-149. 